\title{
La influenza en el Estado de México y su relación climática. De la pandemia a la estacionalidad
}

\author{
The influenza in the Estado de Mexico and its climatic \\ relation. From the pandemic to the seasonal nature
}

\author{
José de Jesús Coria-Lorenzo, ${ }^{1}$ Enrique Rafael Ortiz-García, ${ }^{2}$ Xochitl Mirón-Calderón, ${ }^{3}$ Elizabeth Dávila-Chávez, \\ Evelyn Pla-Esquivel, ${ }^{5}$ Leo Edgar Mancilla-Bernal ${ }^{6}$
}

\begin{abstract}
Resumen
OBJETIVO: Conocer si los factores climáticos, ambientales y geográficos influyen en la distribución de casos de influenza en los municipios del Estado de México.

MATERIALES Y MÉTODOS: Análisis descriptivo y retrospectivo de casos positivos para algún tipo de influenza (semanas epidemiológicas de la 40 a la 20) registrados de 2009 a 2016 en los municipios y jurisdicciones del Estado de México. Se analiza la circulación del virus acorde con los puntos cardinales, condiciones climáticas, estacionales y geográficas en relación con su cercanía con la Ciudad de México.

RESULTADOS: De 17,177 casos sospechosos analizados, se encontraron 3829 casos positivos, la mayoría (2993 [78.2\%]) se concentraron en 19 municipios, y el resto (836 $[21.8 \%]$ ) en otros municipios diferentes. La circulación de los virus fue, principalmente, en lugares al norte de la Ciudad de México, independientemente de si se registraron por municipio o jurisdicción. Los municipios con mayor registro de casos de influenza fueron: Nezahualcóyotl, Ecatepec, Tlalnepantla, Naucalpan, Nicolás Romero, Coacalco y Cuautitlán. Los dos primeros destacan por ser los de mayor población en el Estado. CONCLUSIONES: La distribución de los casos de influenza fue, prioritariamente, en las zonas con clima seco estepario y semiseco en donde la formación de microclimas, la latitud, la circulación de los vientos y otros favorecen que el virus encuentre las condiciones idóneas para su propagación.
\end{abstract}

PALABARAS CLAVE: Influenza; municipios; México; pandemia; microclimas; clima.

Abstract

OBJECTIVE: To know if the climatic factors or environmental and geographic influence or were influential in the distribution of cases of influenza in the 125 municipalities of the Estado de México.

MATERIAL AND METHODS: Descriptive and retrospective analysis of positive cases for some type of influenza. We reviewed the annual concentrates of databases in Excel with a positive result for some type of influenza from the pandemic (2009) until the end of the 2016 season (epidemiological week 20). As well as the municipalities and jurisdictions where there were such cases of influenza. We analyze the circulation of the virus according to the cardinal points as well as the climatic and geographic conditions in relation to its proximity to the Mexico City).

RESULTS: Of one total 17177 suspected cases analyzed, 3829 positive cases were found, of which the majority (2993 [78.1\%]) focused only in 19 municipalities, and the rest (836 $[21.8 \%]$ ) were presented in the different towns. The circulation of the virus was mainly in those places located to the north of the Mexico City, regardless if it is registered as a municipality or jurisdiction. The municipalities with the largest registry of cases of influenza were: Nezahualcoyotl, Ecatepec, Tlalnepantla, Naucalpan, Nicolás Romero, Coacalco and Cuautitlán.

CONCLUSIONES: The distribution of cases of influenza was, mainly, in areas with dry steppe and semi-dry climate where the formation of microclimates, latitude, circulation of winds and others favor that the virus finds the ideal conditions for its spread. KEY WORDS: Influenza; Municipalities; Mexico; Pandemic; Microclimates; Climate.

\footnotetext{
1 Infectólogo pediatra, asesor de la Subdirección de Epidemiología del Instituto de Salud del Estado de México, responsable estatal del Programa de Influenza. Adscrito al Departamento de Infectología del Hospital Infantil de México Federico Gómez, Ciudad de México.

2 Subdirector de Epidemiología del Instituto de Salud del Estado de México. 3 Jefe del Departamento de Enfermedades trasmisibles y micobacteriosis.

${ }^{4}$ Ex-directora general del Instituto de Salud del Estado de México.

${ }^{5}$ Responsable estatal de PFA y Apoyo Programa de influenza.

${ }^{6}$ Geógrafo encargado de Planeación de Unidades Médicas Móviles del Programa de Fortalecimiento a la Atención Médica.
}

Recibido: 29 de septiembre 2017

Aceptado: 11 de mayo 2018

Correspondencia

José de Jesús Coria Lorenzo jjcoril@yahoo.com

Este artículo debe citarse como Coria-Lorenzo JJ, Ortiz-García ER, Mirón-Calderón X, Dávila-Chávez $E$, Pla-Esquivel E, Mancilla-Bernal LE. La influenza en el Estado de México y su relación climática. De la pandemia a la estacionalidad. Acta Pediatr Mex. 2018;39(5):289-297. 


\section{INTRODUCCIÓN}

La directora general de la Organización Mundial de la Salud (OMS), Margaret Chan, el director ejecutivo del Programa Medioambiental de las Naciones Unidas (ONU), Erik Solheim, y el secretario general de la Organización Mundial Meteorológica (WOM por sus siglas en inglés), Petteri Taalas, publicaron una carta en la que avisan que la contaminación del aire causa, cada año, 6.5 millones de muertes en el mundo. ${ }^{1}$ Se ha hecho patente un efecto de los cambios provocados en la salud humana relacionados con la temperatura del aire, sobre todo las enfermedades respiratorias en las que el tipo de clima tiene influencia en su incidencia. Por ejemplo, el clima frío en Ecuador se ha asociado con $25 \%$ de las enfermedades respiratorias agudas. La temperatura seca del aire, aunada a climas fríos, también se ha relacionado con episodios de rinitis, asma y enfermedades alérgicas. Se reporta la propagación de enfermedades infecciosas y vectoriales como consecuencia del cambio climático, al que se añaden las enfermedades de origen hidro-alimentario y respiratorio. La diversidad de climas y microclimas en una región, junto con los cambios abruptos en un periodo muy corto de un sitio a otro son un factor favorable para la aparición de enfermedades relacionadas con cada época estacional; con el frío y humedad son más comunes las enfermedades respiratorias agudas y aumenta el riesgo de enfermedades como gripe (influenza), resfriado común, neumonía, laringitis, bronquitis y sinusitis. ${ }^{2-4}$

El Instituto Nacional de Ciencias de la Salud y Medio Ambiente (NIEHS por sus siglas en inglés) destaca que el cambio climático puede ser un incentivo para la migración de una enfermedad, como la influenza. Su ciclo consiste en atacar una población con muchas personas sin inmunidad previa y propagarse rápidamente, ocurre durante todo el año, en las naciones o ciudades de latitudes entre $\operatorname{los} 23^{\circ}$ y $90^{\circ}$ Norte y Sur donde el clima frio y templado es más definido (como ocurre en el Estado de México (Figura 1). Los reportes de la bibliografía consideran que los casos se concentran más durante el invierno. Otros factores ambientales que pueden contribuir a la propagación de la influenza son: la humedad y la temperatura del aire. Cuanto más fría es la temperatura, más tiempo el virus permanece infeccioso en el ambiente y las gotas de saliva que cargan el virus permanecen en el aire por más tiempo dispersándose a más distancia cuando hay poca agua en forma de vapor. Así, durante el invierno que es frío y seco, las gotitas emitidas por la tos o el estornudo de enfermos recorren una distancia mayor y duran más tiempo en el aire, aumentando mucho las probabilidades de contraer gripe. ${ }^{5,6}$

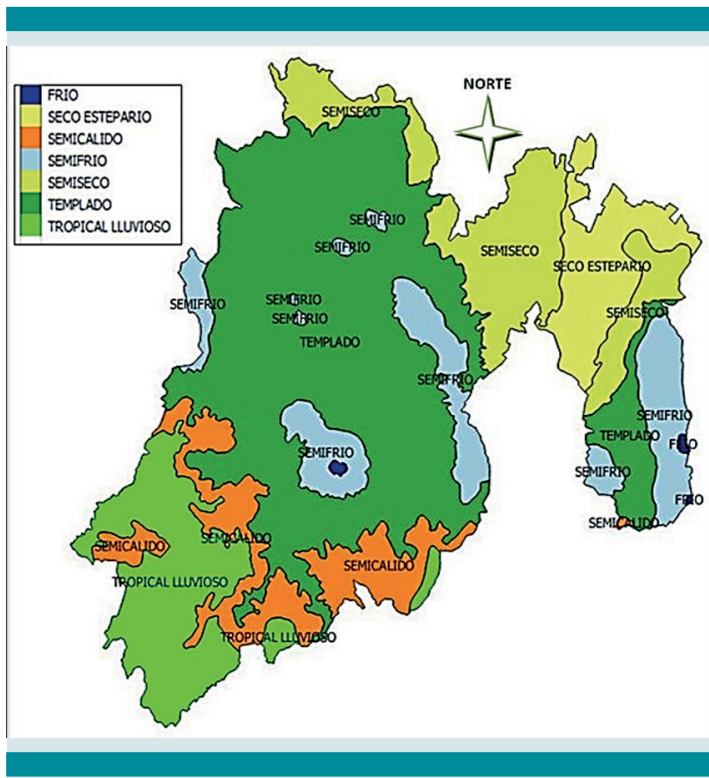

Figura 1. Diferencia de climas en el Estado de México congruentes con la clasificación de Köpen; modificada por Enriqueta García.

Como parte de la vigilancia efectuada en el Estado de México en cuanto a influenza, en el mapa estatal se observa que ésta se ha centralizado en los municipios conurbados al norte de la Ciudad de México. En estos influye el cambio climático 
de la troposfera que favorece las enfermedades de las vías respiratorias, además de la influencia que también ejerce el fenómeno de ventilación, las vías aéreas y el pulmón, como tal están expuestas continuamente a microrganismos ambientales, los que con frecuencia causan infecciones que van desde las de vías aéreas altas hasta las bajas.

El objetivo de este estudio fue: conocer si los factores climáticos, ambientales y geográficos influyen en la distribución de casos de influenza en los municipios del Estado de México. ${ }^{7,8,9}$

\section{MATERIALES Y MÉTODOS}

Análisis descriptivo y retrospectivo de casos positivos para algún tipo de influenza registrados de 2009 a 2016 en los municipios y jurisdicciones del Estado de México. Se revisaron los concentrados anuales de todos los casos reportados como positivos para algún tipo de virus (recolectados mediante la vigilancia epidemiológica de las Unidades de Salud Monitoras de Influenza) confirmados por el laboratorio estatal, que cuenta con reactivos y equipo certificado que permite una excelente correlación de diagnóstico específico, y que se han resguardado en bases de Excel a partir de la pandemia de 2009 hasta el término de la temporada 2016 (semana epidemiológica 40 de 2009 a la semana epidemiológica 20 de 2016). Estos datos están en el departamento de Micobacteriosis y enfermedades trasmisibles de la Subdirección de Epidemiología del Instituto de Salud del Estado de México. Estos reportes o registros se capturaron en una plataforma diseñada ex profeso por la Dirección General de Epidemiología como parte de la estrategia de vigilancia centinela de la influenza pandémica. ${ }^{10}$

Se realizó un análisis descriptivo de cada una de las temporadas analizadas para determinar, primero, frecuencias simples y acumuladas de presentación por cada temporada (2009-2010,
2010-2011, 2011-2012, 2012-2013, 2013-2014, 2014-2015, у 2015-2016).

Para evidenciar por qué la mayoría de casos de influenza se centralizó en los municipios del Norte y del Nor-Este de la Ciudad de Mexico se efectuó un análisis, mediante un mapa de velocidades regionales, de la circulación de los vientos y temperatura del aire que pudiese influir con la cercanía de la Ciudad de México y estos municipios en cuanto a mayor diseminación del virus. ${ }^{11} \mathrm{Al}$ respecto, la Figura 2 hace esta correlación de la circulación de los vientos entre el Estado de México y la Ciudad de México.

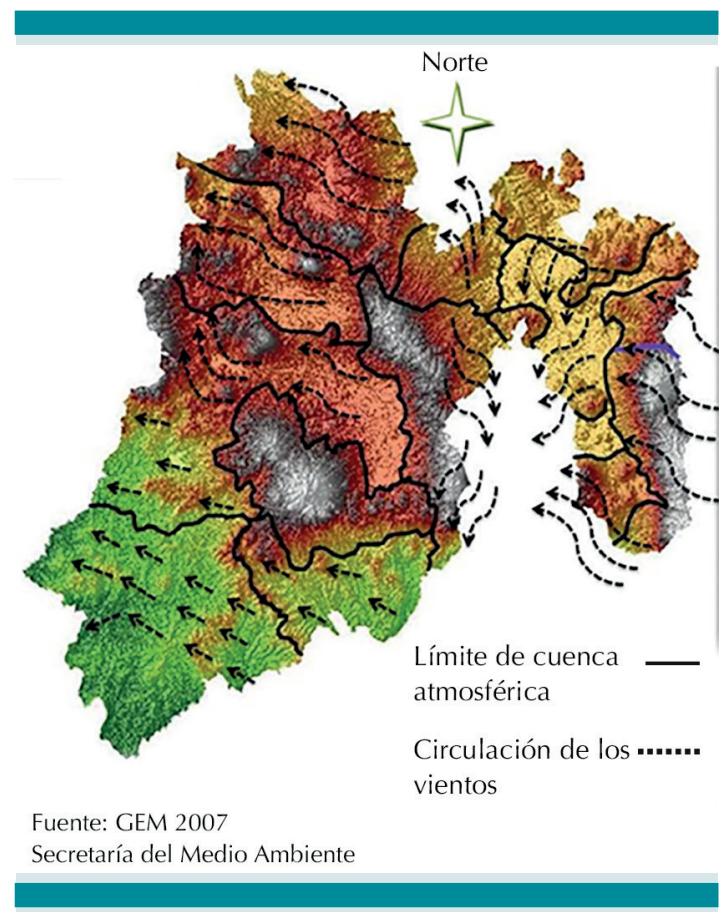

Figura 2. Descripción de la circulación de los vientos en el Estado de México, con predominio Este a Oeste.

\section{RESULTADOS}

Se encontraron registros de 17177 casos sospechosos, de los que 3829 (22.2\%) resultaron positivos para algún tipo de virus influenza. 
Predominaron desde la pandemia hasta finales de 2016 (las siete temporadas analizadas) AH1N1PDM-09 con 2227 casos (58.16\%), seguido de $\mathrm{AH} 3$ (734 casos), influenza A endémica (475 casos) e influenza B con 393 casos.

Con base en la distribución por municipios, de los 125 que cuenta el Estado de México, solo en 19 se detectó el mayor número de casos confirmados de influenza a lo largo de las siete temporadas de influenza analizadas. Por igual, en algunos otros no se registró ningún caso y en otros hubo un registro mínimo de eventos. En el Cuadro 1 se señalan los casos de influenza por municipio y temporada. En primer lugar, Nezahualcóyotl con 549 casos, seguido de Naucalpan con 490, Ecatepec con 415 y Toluca con 315 casos, respectivamente, de un total de 2993 casos en los 19 principales municipios. De éstos, los que menos casos registraron fueron Atlacomulco, Tepotzotlán y Malinalco con 18 - 9 y 9 casos respectivamente. Los otros casos confirmados (836) sucedieron en los 106 municipios restantes. El Estado de México es el más poblado de la República, con 17,363,387 habitantes según el reporte de 2017 del Consejo Nacional de Población. ${ }^{12}$

La vigilancia epidemiológica de la influenza en el Estado de México se evalúa por jurisdicciones, 19 en total; 11 de ellas tienen el mismo nombre que su municipio. Al evaluar la presentación de casos de influenza por jurisdicción se observó que se registró un número menor de eventos (154 casos menos). Por jurisdicción se registraron 2839 casos; en primer lugar: Nezahualcóyotl (549 casos), en segundo Naucalpan (490 casos), seguidos de Ecatepec con 415 y Toluca con 315 casos, respectivamente. Esta distribución de casos por temporada en relación con la jurisdicción que lo reportó, se muestra en el Cuadro 2. La relación real de casos se lleva a cabo por municipios y las Unidades de Salud Monitoras de Influenza correspondientes. El hecho de separar municipios vs jurisdicciones, fue para el caso de evaluar el objetivo del estudio; es decir, si la prevalencia de circulación de virus era igual por jurisdicción que por municipios.

Al separar las colindancias de los municipios con la Ciudad de México se observó que 10 de ellos se localizan al Norte, 3 al Suroeste, otros 3 al Este, y 3 más, cada uno respectivamente, al Sureste, Oeste y Noroeste de la Ciudad de México (Cuadro 1). Por jurisdicción, 6 colindan al Norte de la Ciudad de México; 5 tienen el mismo nombre que su municipio (Atizapán de Zaragoza, Cuautitlán, Ecatepec, Naucalpan). Una jurisdicción (Teotihuacán) colinda al Noreste. Por igual, tres jurisdicciones colindan al Suroeste; dos de ellas con mismo nombre que su municipio (Tenancingo y Tejupilco). A diferencia de los municipios en donde tres colindan al Este, solo dos jurisdicciones del mismo nombre que sus municipios (Nezahualcóyotl y Texcoco) tienen esta distribución geográfica. Al Sureste solo encontramos la jurisdicción de Amecameca, y al Oeste a diferencia de los municipios donde solo hubo uno (Toluca), aquí tenemos 3 jurisdicciones colindantes: Xonacatlán, Toluca (mismo nombre que él municipio) y Valle de Bravo. Por igual al Noroeste en cuanto a municipios hubo uno colindante (Atlacomulco), mientras que por jurisdicción observamos 3; la misma de Atlacomulco, así como Jilotepec e Ixtlahuaca (Cuadro 2); Las colindancias de los diferentes municipios y su correlación con el predominio de los casos de influenza, acorde con los Cuadros 1 y 2 se describen en la Figura 3.

\section{DISCUSIÓN}

Al evaluar el clima en el Estado de México se encontró que los climas existentes en la entidad mexiquense, según la clasificación de Köpen, modificada por Enriqueta García y adaptada para las condiciones de la República Mexicana son: templado, semifrío y frio en las zonas montañosas, seco estepario y semiseco en la región del 
Coria-Lorenzo JJ, et al. Influenza y la importancia climática

Cuadro 1. Casos de influenza por municipio y temporada

\begin{tabular}{|c|c|c|c|c|c|c|c|c|}
\hline Municipios & 2009-2010 & 2010-2011 & 2011-2012 & 2012-2013 & 2013-2014 & 2014-2015 & 2015-2016 & Totales \\
\hline \multicolumn{8}{|c|}{ Municipios al Norte de la Ciudad de México } & 1790 \\
\hline $\begin{array}{l}\text { Atizapán de } \\
\text { Zaragoza }\end{array}$ & 50 & 21 & 79 & 21 & 33 & 21 & 49 & 274 \\
\hline Cuautitlán & 14 & 1 & 13 & 3 & 21 & 9 & 18 & 79 \\
\hline C. Izcalli & 7 & 3 & 7 & 1 & 9 & 3 & 11 & 41 \\
\hline Coacalco & 8 & 2 & 10 & 3 & 16 & 4 & 6 & 49 \\
\hline Ecatepec & 129 & 20 & 53 & 14 & 91 & 8 & 100 & 415 \\
\hline Naucalpan & 102 & 53 & 109 & 40 & 56 & 9 & 121 & 490 \\
\hline Tecámac & 11 & 1 & 7 & 1 & 24 & 2 & 21 & 67 \\
\hline Tepotzotlán & 1 & 0 & 2 & 0 & 4 & 0 & 2 & 9 \\
\hline Tlalnepantla & 111 & 18 & 47 & 15 & 41 & 18 & 54 & 304 \\
\hline Tultitlán & 13 & 2 & 8 & 2 & 20 & 4 & 13 & 62 \\
\hline \multicolumn{8}{|c|}{ Municipios al Suroeste de la Ciudad de México } & 105 \\
\hline Malinalco & 2 & 0 & 1 & 1 & 1 & 2 & 2 & 9 \\
\hline Tejupilco & 6 & 1 & 12 & 1 & 4 & 8 & 13 & 45 \\
\hline Tenancingo & 1 & 0 & 0 & 1 & 7 & 8 & 34 & 51 \\
\hline \multicolumn{8}{|c|}{ Municipios al Este de la Ciudad de México } & 688 \\
\hline Chimalhuacán & 20 & 1 & 15 & 3 & 25 & 4 & 31 & 99 \\
\hline Nezahualcóyotl & 145 & 27 & 66 & 18 & 119 & 54 & 120 & 549 \\
\hline Texcoco & 15 & 0 & 4 & 5 & 9 & 0 & 7 & 40 \\
\hline \multicolumn{8}{|c|}{ Municipios al Sureste de la Ciudad de México } & 77 \\
\hline Chalco & 4 & 5 & 1 & 6 & 24 & 5 & 32 & 77 \\
\hline \multicolumn{8}{|c|}{ Municipios al Oeste de la Ciudad de México } & 315 \\
\hline Toluca & 47 & 17 & 76 & 29 & 68 & 13 & 65 & 315 \\
\hline \multicolumn{8}{|c|}{ Municipios al Noroeste de la Ciudad de México } & 18 \\
\hline Atlacomulco & 2 & 0 & 1 & 0 & 4 & 2 & 9 & 18 \\
\hline Totales & 688 & 172 & 511 & 164 & 576 & 174 & 708 & 2993 \\
\hline
\end{tabular}

Noreste del estado, semicálidos y cálidos en las regiones Sur y Suroeste. ${ }^{13,14}$ Figura 1

En cuanto al patrón de la circulación de los vientos en la entidad, la Secretaría del Medio Ambiente del Gobierno del Estado de México (2007), a través de la Dirección General de Prevención y Control de la Contaminación Atmosférica señala que, la circulación general de la atmósfera se rige por encima de los 1000 metros sobre el nivel del mar. La circulación de los vientos, ya dentro del Estado de México es en dirección Este a Oeste, pero ciertos factores naturales, como las elevaciones montañosas o rocosas y su ubicación que delimitan los límites de la cuenca atmosférica, dan lugar a la concentración de calor en los municipios conurbados del Valle de México. Figura 2 
Cuadro 2. Casos de influenza por jurisdicción y temporada

\begin{tabular}{|c|c|c|c|c|c|c|c|c|}
\hline Jurisdicción & 2009-2010 & 2010-2011 & 2011-2012 & 2012-2013 & 2013-2014 & 2014-2015 & 2015-2016 & Totales \\
\hline \multicolumn{8}{|c|}{ Jurisdicciones al Norte de la Ciudad de México } & 1635 \\
\hline $\begin{array}{l}\text { Atizapán de } \\
\text { Zaragoza }\end{array}$ & 50 & 21 & 79 & 21 & 33 & 21 & 49 & 274 \\
\hline Cuautitlán & 21 & 4 & 20 & 4 & 30 & 12 & 29 & 120 \\
\hline Zumpango & 2 & 0 & 3 & 0 & 8 & 0 & 19 & 32 \\
\hline Ecatepec & 129 & 20 & 53 & 14 & 91 & 8 & 100 & 415 \\
\hline Naucalpan & 102 & 53 & 109 & 40 & 56 & 9 & 121 & 490 \\
\hline Tlalnepantla & 111 & 18 & 47 & 15 & 41 & 18 & 54 & 304 \\
\hline \multicolumn{8}{|c|}{ Jurisdicciones al Noreste de la Ciudad de México } & 8 \\
\hline Teotihuacán & 0 & 1 & 1 & 0 & 1 & 1 & 4 & 8 \\
\hline \multicolumn{8}{|c|}{ Jurisdicciones al Suroeste de la Ciudad de México } & 194 \\
\hline Tenango del Valle & 0 & 0 & 6 & 5 & 41 & 9 & 37 & 98 \\
\hline Tejupilco & 6 & 1 & 12 & 1 & 4 & 8 & 13 & 45 \\
\hline Tenancingo & 1 & 0 & 0 & 1 & 7 & 8 & 34 & 51 \\
\hline \multicolumn{8}{|c|}{ Jurisdicciones al Este de la Ciudad de México } & 589 \\
\hline Nezahualcóyotl & 145 & 27 & 66 & 18 & 119 & 54 & 120 & 549 \\
\hline Техсосо & 15 & 0 & 4 & 5 & 9 & 0 & 7 & 40 \\
\hline \multicolumn{8}{|c|}{ Jurisdicciones al Sureste de la Ciudad de México } & 33 \\
\hline Amecameca & 1 & 0 & 0 & 0 & 3 & 2 & 27 & 33 \\
\hline \multicolumn{8}{|c|}{ Jurisdicciones al Oeste de la Ciudad de México } & 368 \\
\hline Xonacatlán & 2 & 0 & 2 & 0 & 1 & 0 & 9 & 14 \\
\hline Toluca & 47 & 17 & 76 & 29 & 68 & 13 & 65 & 315 \\
\hline Valle de Bravo & 0 & 0 & 0 & 0 & 1 & 2 & 36 & 39 \\
\hline \multicolumn{8}{|c|}{ Jurisdicciones al Noroeste de la Ciudad de México } & 45 \\
\hline Atlacomulco & 2 & 0 & 1 & 0 & 4 & 2 & 9 & 18 \\
\hline Jilotepec & 0 & 1 & 0 & 0 & 1 & 0 & 9 & 11 \\
\hline Ixtlahuaca & 3 & 0 & 0 & 0 & 4 & 0 & 9 & 16 \\
\hline Totales & 637 & 163 & 473 & 148 & 481 & 158 & 714 & 2839 \\
\hline
\end{tabular}

Lo anterior favorece que el comportamiento de las corrientes de viento durante las diferentes estaciones del año sea cambiante. Por ejemplo, en Toluca, en el equinoccio de primavera (marzo, abril y mayo) predominantemente son hacia el Sur suroeste, hacia el Noreste y al Sureste, sobre todo en marzo y abril. Permanecen igual en mayo pero con dirección predominante hacia el Noreste y Noroeste y Oeste noroeste. En el solsticio de verano (junio, julio y agosto) mantiene una dirección hacia el Noroeste, Este noreste y Noreste y sobre todo hacia el Sureste, Sur sureste y Este sureste. Predominan al Noreste y al Sureste en junio y agosto. Durante el equinoccio de otoño (septiembre, octubre y noviembre), los vientos tienen una dirección pre- 


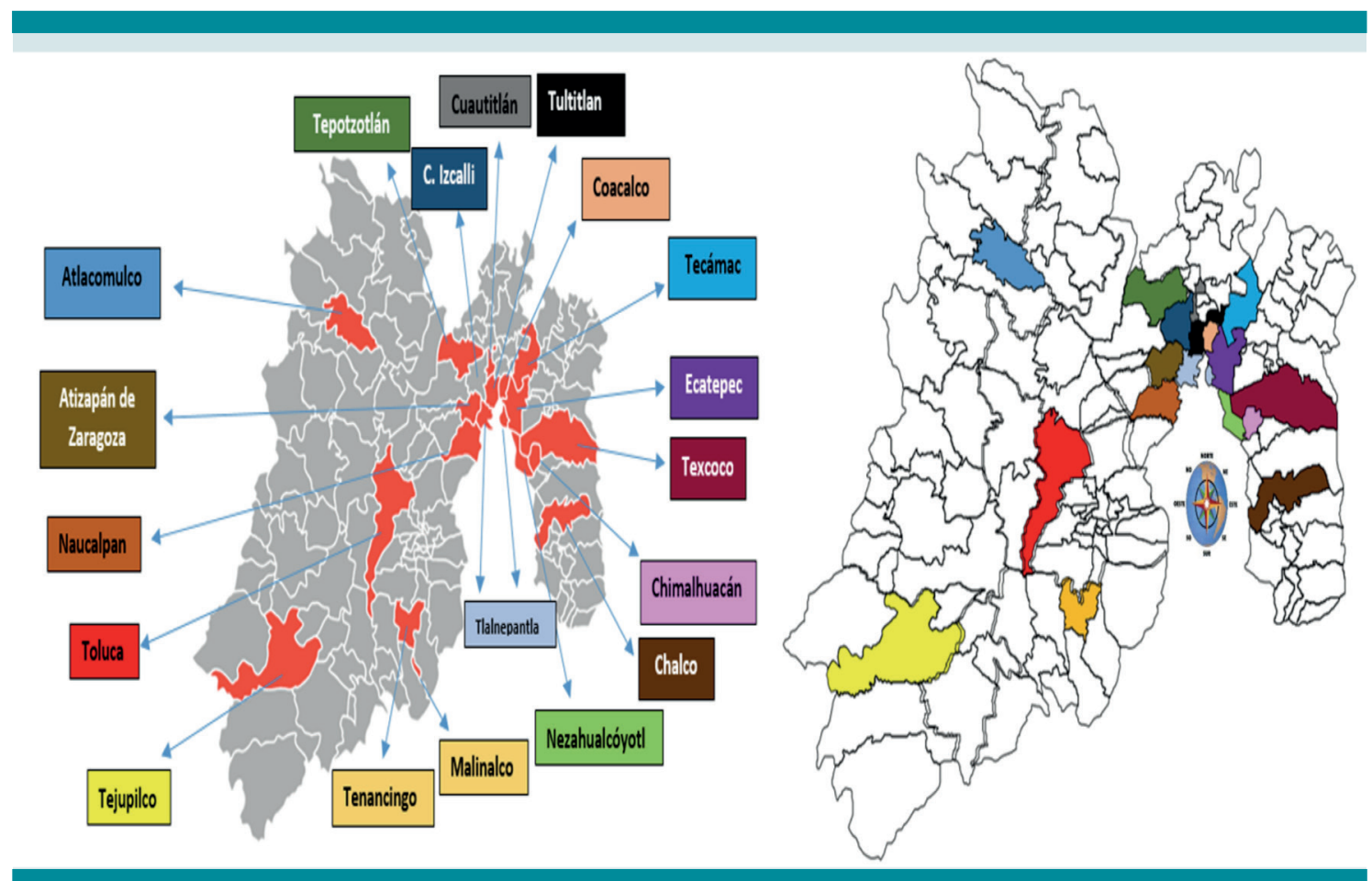

Figura 3. Se señalan las colindancias de los diferentes municipios del Estado de México con la Ciudad de México. Su correlación con el predominio de los casos de influenza referida en los cuadros 1 y 2.

dominantemente Noreste seguida de dirección Sureste y muy poco hacia el Sur suroeste, sobre todo en noviembre. Los vientos son más fuertes en el verano que en el otoño, mientras que durante el solsticio de invierno (diciembre, enero y febrero) las masas de aire afectan el territorio con vientos en dirección sobre todo al sur (Sur suroeste, Suroeste, Sur sureste y Sureste) seguido de corrientes hacia el Noreste y Este noreste. ${ }^{15,16}$

Los factores orográficos afectan la dirección del viento debido a la variación de altura en las elevaciones principales y su ubicación; la diferencia de los vientos es ligeramente diferente a la circulación general de los mismos, pero ambos se vuelven importantes cuando el grado de radiación solar se concentra en determinada superficie, las barreras montañosas, presión atmosférica y el comportamiento de las masas de aire que contienen llevan a definir unidades de espacio geográfico que por dichos rasgos naturales hacen diferente a otras zonas colindantes delimitando una cuenca atmosférica. El 73\% del Estado tiene clima templado subhúmedo, localizado en los valles altos del Norte, centro y Este; $21 \%$ es cálido subhúmedo y se encuentra hacia el Suroeste, $6 \%$ seco y semiseco, presente en el noreste, y $0.16 \%$ clima frío, localizado en las partes altas de los volcanes. ${ }^{8,9,17,18}$

Esta diversidad en el relieve del Estado de México, como tal, da lugar a una variación de climas de un sitio a otro así como cambios abruptos de temperaturas que pareciera a ciertas distancias del traslado de la población de un lugar a otro; dentro del mismo Estado, o más común del Estado a la Ciudad de México o, viceversa, ser un factor condicionante que favorece la propa- 
gación de cepas virales, incluida la de Influenza, y ante la falta de humedad aumenta el riesgo de enfermedades respiratorias agudas.

\section{ANÁLISIS}

Como puede observarse en la figura de los climas del Estado de México y en los cuadros de casos totales de influenza durante las temporadas 2009-2016 (Cuadros 1,2), los municipios con mayor número de casos de influenza se ubican en dirección Norte, Noreste y Noroeste mismos que se encuentran dentro de las zonas definidas con climas: seco, semiseco estepario, semifrío, templado subhúmedo, donde el virus encuentra las condiciones idóneas para su propagación.

El Estado de México, como lo muestra el mapa climático, está conformado por una variedad de microclimas, que se ven reforzados por el factor humano que, por igual, contribuye al cambio de estos microclimas. Este factor, en estas áreas, es la urbanización del espacio geográfico que da origen a la concentración de radiación solar en ciertas zonas. Ejemplos de estos microclimas son los municipios de mayor registro de casos, como: Nezahualcóyotl, Ecatepec, Tlalnepantla, Naucalpan, Nicolás Romero, Coacalco y Cuautitlán, que también concentran el mayor número de densidad de población del país, ejemplo de ello es el caso de Ecatepec con $10857.66 \mathrm{hab} / \mathrm{km}^{2}$ que tiene el tercer lugar de casos de influenza en el Estado.

Si bien es cierto que la migración de enfermedades es resultado del cambio climático global, así mismo con base en lo descrito se ha identificado la correlación de los siguientes factores geográficos para la propagación del virus de influenza: clima, latitud, circulación de los vientos, topografía, radiación solar, contaminación ambiental y actividad humana.

Como tal, en los municipios con casos de influenza con clima semifrío (Toluca y Atlacomulco) éste puede ser otro factor porque el virus permanece infeccioso en este tipo de ambiente. En otras regiones con clima tropical lluvioso y semicálido no se identifica una posible relación con factores geográficos que induzcan a la propagación del virus, por lo que consideramos probable que los casos identificados se deben al traslado de población por actividades de trabajo y comercio a los lugares donde el virus de influenza es frecuente $y$, de hecho, como tal en municipios del Estado de México con este clima, no se registran casos de influenza.

\section{CONCLUSIONES}

Quedó demostrado que en ciudades cuyo grado de contaminación es bastante elevado, y en otras donde las variaciones del clima son cambiantes (vientos, Iluvias, humedad, poca humedad, transición entre calor - clima fresco - descenso de temperatura) o inversión térmica, las infecciones respiratorias: influenza, resfriado común, bronquitis y asma son las que más se observan. Aunado a ello, su agudización durante las épocas de invierno, otoño y primavera es rara. En invierno debido a los cambios bruscos de temperatura y los vientos fríos; en otoño por los vientos fuertes que favorecen la polinización y en primavera, se ven favorecidas las infecciones por el aire seco. ${ }^{1-3,19}$

En el Estado de México la diversidad de climas, pero predominantemente templado subhúmedo, seco y semiseco de los municipios colindantes con la Ciudad de México, así como su topografía y las corrientes o circulación predominante de los vientos es lo que ha favorecido que la mayoría de casos observados se concentren en los municipios o jurisdicciones localizadas al Norte, noreste y suroeste en relación con la Ciudad de México. Es posible, aunque no puede asegurarse, que la cotidiana migración de personas del Estado de México a la Ciudad de México y, viceversa, así como la densidad poblacional de municipios como Ecatepec o Ciudad Nezahualcóyotl, sea un factor extra del mayor número de casos encontrados en los municipios más cercanos a la capital del país. 
Indirectamente pudiéramos inferir o considerar que estas corrientes de los vientos explicarían porqué la Ciudad de México ocupó, por ejemplo en 2017, el segundo lugar de casos ETI/IRAG $(4,407)$ después de Nuevo León $(4,820)$, pero el primer lugar de casos positivos a influenza (778 casos).

Respecto al virus de la influenza en cuanto a sus características de experimentar cambios o mutaciones antigénicas (shift-drift), pero sobre todo las mutaciones antigénicas de virus que infectan otros animales (pájaros, puercos, aves de corral) y que infectan al hombre directamente sin una recombinación genética, podría explicar lo que se ha visto en cuanto a las infecciones en el humano expuesto a mercados de aves al aire libre o criaderos de aves (patos, palomas, pollos, pájaros, etc.) donde las condiciones climáticas han influido para el contagio humano con los virus aviar. El virus influenza A infecta, entre otros animales, a patos, pollos y puercos y seguramente una de las vías de que exista esta diseminación entre animales y el hombre pudiese ser el factor climático y ambiental que rodea ciertas comunidades. ${ }^{20-21}$

\section{REFERENCIAS}

1. UNIVADIS ${ }^{\circledR}$ Noticias Médicas. http://www.univadis.mx/ medical-news/91/La-contaminacion-causa-cada-ano6-5-millones-de-muertes 11/01/2017. Fecha de consulta: 7 de marzo 2017.

2. Jama Saa MV. Agentes causales de infecciones respiratorias agudas presenteVs en niños y niñas de 1-4 años que acuden al subcentro de salud. 7 de octubre del área 2, Quevedo de la provincia Los Ríos, durante el segundo semestre del año 2010 [Internet]. [Tesis de Grado de Licenciada en Enfermería]. Babahoyo, Ecuador: Universidad Técnica de Babahoyo. Facultad de Ciencias de la Salud, 2011.

3. Corona B. Influencia del régimen térmico meteorológico sobre la incidencia de asma bronquial y enfermedades respiratorias agudas. Municipio Playa, 2004. [Tesis de Maestría de Salud ambiental]. La Habana: Instituto Nacional de Higiene, Epidemiología y Microbiología, 2005.

4. Pérez-Rodríguez AE. Variabilidad y cambios climáticos. Impacto sobre algunas enfermedades infecciosas. Rev Haban Cienc Méd. 2011; 10(3):372-81.

5. A Human Health Perspective on Climate Change, 2010: 4, 13. Fecha de consulta: 7 de marzo 2017. https://www. niehs.nih.gov/research/programs/geh/climatechange/ health_impacts/

6. OPS 2009 http://blog.h1n1.influenza.bvsalud.org/ pt/2009/10/15/a-sazonalidade-da-gripe/ Fecha de consulta: 25 de mayo 2017.

7. Coria JJL, Ortiz ERG, Mirón XC, Dávila ECh, Pla EE, Mancilla LEB. La circulación de los virus de influenza en el Estado de México: Del Boom Pandémico a la Endemicidad. Arch Invest Mater-Infan Octubre-Noviembre-2017.

8. Cambio climático: http://www.who.int/mediacentre/ factsheets/fs266/es/ Fecha de consulta: 29 de junio 2016.

9. WO. Quantitative risk assessment of the effects of climate change on selected causes of death, 2030s and 2050s. Geneva: World Health Organization, 2014.

10. Lineamientos para la Vigilancia Epidemiológica de Influenza. Grupo Técnico Interinstitucional del Comité Nacional para la Vigilancia Epidemiológica (CONAVE). SINAVE. Enero 2012.

11. http://www.construaprende.com/docs/44-tablas/363velocidades-regionales-mexico-cfe Fecha de consulta: 25 de mayo 2017.

12. Población de los estados de México (2017). https://www. saberespractico.com/demografia/poblacion-de-losestados-de-mexico/

13. http://www.geographos.com/mapas/fotos/Climatico_ Koppen_Mundo.jpg. Fecha de consulta: 3 de junio 2017.

14. Variabilidad de Climas en México. http://climasdemexico. blogspot.mx/2011/05/clasificacion-climatica-de-koppen. html

15. Gobierno del Estado de México [GEM] (2007). Cuencas Atmosféricas del Estado de México. Secretaría del Medio Ambiente. 2007;12-23.

16. https://es.windfinder.com/windstatistics/toluca. Fecha de consulta: 3 de junio 2017.

17. IPCC. Summary for Policymakers. In: Edenhofer OR, et al. Climate Change 2014, Mitigation of Climate Change Contribution of Working Group III to the Fifth Assessment Report of the Intergovernmental Panel on Climate Change. Cambridge, United Kingdom and New York, NY, USA.: Cambridge University Press, 2014.

18. 18. Clima Estado De México. INEGI, Carta de Climas. www. cuentame.inegi.org.mx/monografias/informacion/mex/ territorio/clima.aspx?...

19. Cambio climático: el causante de muchas enfermedades respiratorias. http://vidasana.sv/enfermedades-respiratorias-causadas-por-el-cambio-de-clima/http://www.who. int/mediacentre/factsheets/fs266/es/ Fecha de consulta: 12 de junio 2017.

20. Li Q, Zhou L, Zhou M, Chen Z, Li F, Wu H, Xiang N, et al. Epidemiology of Human Infection with Avian Influenza A(H7N9) Virus in China. N. Engl J Med. 2014;370:520-32. DOI: 10.1056/NEJMoa1304617

21. Farooqui $A$, et al. Probable Hospital Cluster of H7N9 Influenza Infection. N Engl J Med. 2016;374 (6):596-98. DOI: 10.1056/NEJMc1505359 